\title{
Apple Snail Perivitellin Precursor Properties Help Explain Predators' Feeding Behavior
}

\author{
María Pilar Cadierno ${ }^{1}$ \\ Marcos Sebastián Dreon ${ }^{1,2}$ \\ Horacio Heras ${ }^{1,3, *}$ \\ ${ }^{1}$ Instituto de Investigaciones Bioquímicas de La Plata \\ (INIBIOLP), Consejo Nacional de Investigaciones Científicas \\ y Técnicas-Universidad Nacional de La Plata (CONICET- \\ UNLP), La Plata, Argentina; ${ }^{2}$ Cátedra de Bioquímica y \\ Biología Molecular, Facultad de Ciencias Médicas, UNLP, La \\ Plata, Argentina; ${ }^{3}$ Cátedra de Química Biológica, Facultad de \\ Ciencias Naturales y Museo, UNLP, La Plata, Argentina
}

Accepted 12/28/2016; Electronically Published 4/12/2017

Online enhancements: appendix figures.

\begin{abstract}
In contrast with vitellogenin maturation, it is unknown whether gastropod perivitellin precursors are subject to large structural changes. The gastropod reproductive tract includes an accessory organ, the albumen gland (AG), that produces and secretes perivitelline fluid. In the apple snail Pomacea canaliculata, the large, reddish-pink AG provides eggs with perivitellins that are defensive against predators. Although the AG makes a considerable contribution to apple snail biomass, field observations indicate that it is rejected by avian and mammalian predators, although the underlying reason remains unknown. By analyzing the structurefunction properties of $P$. canaliculata perivitellin precursors, we provide insight into perivitellin maturation and its relationship with apple snail predator feeding behavior. Structural analysis using small-angle X-ray scattering, absorption and fluorescence spectroscopy, circular dichroism, electrophoresis, chromatography, and partial proteolysis showed that the size, shape, and structure of perivitellin precursors resemble those of egg mature forms. Functional analysis indicates that the precursors of the defensive perivitellins ovorubin (PcOvo) and perivitellin-2 (PcPV2) are highly stable and antinutritive, withstanding proteinase digestion and displaying structural stability of their quaternary structure under a wide $\mathrm{pH}$ range (4.0-10.0). Furthermore, AG extracts limit a predator's ability to digest nutrients and are toxic to mice (median lethal concentration $96 \mathrm{~h}$ after administration: $5.9 \mathrm{mg} / \mathrm{kg}$ ). Treated mice displayed neurologic signs similar to those produced by egg PcPV2. Results indicate that apple snails
\end{abstract}

*Corresponding author; e-mail: h-heras@med.unlp.edu.ar.

Physiological and Biochemical Zoology 90(4):461-470. 2017. (C) 2017 by The University of Chicago. All rights reserved. 1522-2152/2017/9004-6084\$15.00. DOI: $10.1086 / 691526$ store active precursors of egg proteins inside the AG, providing evidence that gastropod perivitellin precursors do not experience the large structural processing of invertebrate vitellogenin maturation. These defensive proteins provide the apple snail AG with neurotoxic, antinutritive, and antidigestive activity, a likely explanation for the predators' feeding behavior.

Keywords: neurotoxin, antinutritive protein, snail kite, animal defense, structure-function, defensive protein, toxicity, perivitellin precursor.

\section{Introduction}

A molecular approach was implemented to gain insight into gastropod perivitellin precursor characteristics and to investigate for possible causes of Pomacea canaliculata predator behavior of discarding the albumen gland (AG). We analyzed the structural and functional properties of the precursors of the major egg perivitellins. We hypothesize (1) that unlike vitellogenins, they do not undergo any large posttranslational processing before being incorporated into eggs and (2) that these particles are stored already functional and noxious in the AG, which could explain the predators' discarding behavior.

\section{Vitellogenic Mechanisms in Oviparous Animals} and Gastropod Singularities

Many animal life-history traits are constrained by reproductivetract structure and taxon-specific vitellogenic mechanisms that determine the quantity, quality, and rate of energy (yolk) incorporation into egg (Eckelbarger 1994). During vitellogenesis, oviparous species synthesize lipids, proteins, and carbohydrates either outside or inside the ovary and incorporate them into primary oocytes to serve mainly as energetic and structural sources for embryo development (de Jong-Brink et al. 1983). The major egg yolk proteins usually form complex water-soluble particles called vitellins (Wallace et al. 1967). Vitellin precursors, collectively referred to as vitellogenins, undergo substantial structural changes involving proteolysis before acquiring their mature vitellin conformation (Raikhel and Sappington 2002). However, a physiologically distinct vitellogenic pathway is present in many gastropods. They have evolved an alternative mechanism in which a limited amount of vitellus is included in the eggs, as they coat the fertilized oocyte with a nutritive and protective layer or capsule (termed perivitelline fluid) produced by the AG, a female accessory reproductive organ that is exclusive to gastropods (Runham 1988). Proteins present in the perivitelline fluid have been 
termed perivitellins and would be equivalent to vitellins. However, in contrast with vitellogenins, it is unknown whether perivitellin precursors are active or subject to large structural changes before they reach their final destination. This knowledge gap in gastropods is remarkable, considering the central role of perivitellins in reproduction.

Apple Snails as a Model for the Study of Gastropod Perivitellins

Apple snails (Ampullariidae) are among the largest and most ecologically important freshwater snails, with a large and diverse body of research across several fields, including most metabolic, structural, and functional studies on gastropod perivitellins (Hayes et al. 2015). Most research concerns a single species, $P$. canaliculata (Lamarck, 1822), that possesses the potential to become a model organism (Hayes et al. 2015). Pomacea canaliculata is a South American snail introduced to Asian wetlands and the Pacific islands, where they became an invasive species, a serious pest of aquatic crops, and a vector for human eosinophilic meningoencephalitis, a parasitic disease (Cowie 2002; Lv et al. 2009).

Pomacea canaliculata lay their eggs above the water level and have virtually no reported egg predators worldwide, with the exception of the fire ant Solenopsis geminata (Yusa 2001). This is probably related to the presence of an unusual set of defensive perivitellins, including an aposematic signal as a predator warning (Dreon et al. 2002, 2010, 2013, 2014; Heras et al. 2007). Recently, transcriptomic and proteomic analysis revealed a large maternal investment on perivitelline-fluid proteins (Sun et al. 2012a). The precursors of the most abundant perivitellins, ovorubin (PcOvo) and perivitellin-2 (PcPV2), are studied in Heras et al. (1998). These are exclusively synthesized and stored in the AG (Dreon et al. 2002, 2003; Catalán et al. 2006; Sun et al. 2012b), and they account for $65 \%$ of egg proteins, playing multiple roles, such as nourishing and protecting embryos. PcOvo is an oligomeric protein, composed of subunits ranging from 28 to $35 \mathrm{kDa}$ (Garín et al. 1996), that carries and stabilizes carotenoids, supplying the embryos with a potent membrane antioxidant molecule and giving the reddish-pink pigmentation to eggs (Dreon et al. 2004; Heras et al. 2007). This perivitellin resists digestion and reaches the predator small intestine in a fully active form, as an antinutritive that diminishes rat growth rate (Dreon et al. 2010). The second-most-abundant protein, PcPV2, is also an antinutritive factor. In addition, it displays a potent neurotoxin activity, with a lethal effect on mice. Its structure is unique in nature, combining a lectin $(31 \mathrm{kDa})$ and a poreforming subunit $(67 \mathrm{kDa})$ linked by disulfide bridges (Heras et al. 2008; Dreon et al. 2013). PcOvo and PcPV2 are good candidates for the study of perivitellin precursors, because their functionality is relatively easy to determine.

\section{Apple Snail AG, Perivitellin Precursors, and Adult-Snail Predator Behavior}

In contrast with the scarce egg predators, adult apple snails are preyed on by several species. Among them, the snail kite
Rostrhamus sociabilis, the limpkin Aramus guarauna, and the Norway rat Rattus norvegicus have been the most studied ones (Snyder and Kale 1983; Sykes 1987; Yusa et al. 2000). Kites and limpkins are diurnal hunters that concentrate their foraging activity on lentic water bodies. After finding and capturing a snail, they carry them to feeding perches (kites) or to the shore (limpkins) to consume the soft parts (Tanaka et al. 2006). Rats prey on snails by peeling off the shells with their teeth until they reach the attachment site of the columellar muscle (Yusa et al. 2000). Field observations indicate that these avian and mammalian predators display an intriguing behavior, discarding the AG when feeding on female snails (Snyder and Kale 1983; Sykes 1987; Yusa et al. 2000). This is remarkable, considering that the AG represents a great contribution to female snail body biomass (Estoy et al. 2002), which implies a significant loss of energy and nutrients (M. P. Cadierno, S. Burela, M. S. Dreon, P. R. Martín, and H. Hera, unpublished manuscript). The cause of this behavior is, however, unknown.

\section{Methods}

\section{Sample Preparation}

Females and egg masses with embryos up to morula stage of Pomacea canaliculata were collected in the wild from streams and ponds near the city of La Plata, Buenos Aires Province, Argentina, during its reproductive period (November-March). To get the soluble fraction of these samples, a number of egg masses and dissected AGs were pooled and homogenized in ice-cold $20 \mathrm{mM}$ Tris/HCl buffer, pH 7.5, on a Potter-type homogenizer (Thomas Scientific, Swedesboro, NJ) with a buffer: sample ratio of $3: 1 \mathrm{v} / \mathrm{w}$. The crude homogenate was sequentially centrifuged at $10,000 \mathrm{~g}$ for $20 \mathrm{~min}$ and at $100,000 \mathrm{~g}$ for $50 \mathrm{~min}$; the pellets were discarded. Total soluble protein concentration was determined colorimetrically (Lowry et al. 1951), with bovine serum albumin (BSA) as standard.

For perivitellin purification, the AG and egg soluble fractions were subjected to density gradient ultracentrifugation, as described by Garín et al. (1996). Aliquots containing either the precursors or the mature forms of PcPV2 and PcOvo were pooled, desalted, and concentrated by ultrafiltration in an Amicon Ultra-4 Centrifugal Filter Unit (Millipore, Billerica, MA). Both perivitellin fractions were purified by anion exchange liquid chromatography in a Mono Q HR 10/100 column (AmershamPharmacia, Uppsala, Sweden) coupled to an Agilent 1260 highperformance liquid chromatography (HPLC) system (Agilent Technologies), with a gradient of $0-1 \mathrm{M} \mathrm{NaCl}$ in a $20 \mathrm{mM}$ Tris/ $\mathrm{HCl}$ buffer, $\mathrm{pH}$ 8.5. The $\mathrm{PcOvo}$ peak was further purified by size exclusion chromatography in a Superdex 200 10/300 GL column (Amersham-Pharmacia) with a $20 \mathrm{mM}$ Tris/ $\mathrm{HCl}$ buffer, $\mathrm{pH} 8.5$. Samples were desalted and concentrated after each chromatography step, as described above. The purity of the single peaks was checked by native electrophoresis, and the total protein content was quantified (Lowry et al. 1951). To identify perivitellin origin, we refer to AG perivitellin precursors as agPcOvo and agPcPV2 and to mature egg forms of perivitellins as ePcOvo and ePcPV2. 
Structural Studies of Egg and AG Perivitellins

Polyacrylamide Gel Electrophoresis (PAGE). Native proteins were analyzed by nondissociating PAGE using a gradient of 4\%-20\% acrylamide (Davis 1964; Margolis and Wrigley 1975) and protein subunits by sodium dodecyl sulfate (SDS)-PAGE using a 4\%$20 \%$ polyacrylamide gradient (Laemmli 1970 ). Gels were stained with Coomassie Brilliant Blue R-250 (Sigma Chemical).

Anion Exchange and Size Exclusion Liquid Chromatography. The hydrodynamic volume and the content of superficial charges of the perivitellins were evaluated by comparing their retention time through a Superdex 200 10/300 GL column (AmershamPharmacia) and a Mono Q HR 10/100 column (AmershamPharmacia), respectively. Both columns were coupled to an Agilent 1260 HPLC system (Agilent Technologies). Running conditions were those mentioned for perivitellin purification.

Absorption Spectroscopy. Absorption ultraviolet (UV)-visible spectra were recorded in $20 \mathrm{mM}$ Tris/ $\mathrm{HCl}$ buffer, $\mathrm{pH} 8.5$, at $25^{\circ} \mathrm{C}$ with an Agilent $8453 \mathrm{UV}$-visible spectrophotometer (Agilent Technologies). Spectra were also recorded for agPcOvo preincubated at different $\mathrm{pH}$ values, in order to evaluate the effect of $\mathrm{pH}$ over the carotenoid moiety. Spectral scanning was performed at 1-nm bandwidth, and each spectrum was the average of 10 individual runs. Buffer and light-scattering contributions to raw data values were subtracted.

Circular Dichroism (CD). Far-UV CD spectra (195-250 nm) were performed in a J-810 spectropolarimeter (Jasco) using $0.1-\mathrm{cm}$ cells at $25^{\circ} \mathrm{C}$. Samples were measured at a concentration of $0.5 \mathrm{mg} / \mathrm{mL}$ in $20 \mathrm{mM}$ Tris/HCl buffer, $\mathrm{pH}$ 8.5. Scanning was performed with $0.1-\mathrm{nm}$ bandwidth, $20-\mathrm{nm}-\mathrm{min}^{-1}$ scan speed, and 1-s average time. Each spectrum was obtained by averaging at least five individual runs and corrected for buffer optical activity.

Fluorescence Spectroscopy. Fluorescence spectra were collected on a Perkin-Elmer LS55 Luminescence Spectrometer (PerkinElmer, Norwalk, CT). Tryptophan (Trp) residues were excited at $285 \mathrm{~nm}$ (8-nm slit), and their emissions were recorded between 295 and $440 \mathrm{~nm}$ (8-nm slit). All samples were measured in $20 \mathrm{mM}$ Tris/ $\mathrm{HCl}$ buffer, $\mathrm{pH} 8.5$, at $25^{\circ} \mathrm{C}$ with a $10-\mathrm{mm}$ optical path length quartz cell. Each spectrum was obtained by averaging 10 individual runs. To evaluate perivitellin structural stability at different $\mathrm{pH}$ conditions, solutions of purified agPcOvo and agPCPV2 in ultrapure water were prepared. They were incubated overnight in a series of buffers with a $\mathrm{pH}$ range between 2 and 12. Emission fluorescence for these samples was also recorded as described above.

Small-Angle X-ray Scattering (SAXS). SAXS experiments were performed at the D02A-SAXS2 line in the Brazilian Synchrotron Light Laboratory, Campinas (Sao Paulo). The scattering pattern was detected with a MarCCD bidimensional chargecoupled device assisted by FIT2D software (http://www.esrf.fr
/computing/scientific/FIT2D). The sample cell was built with two parallel mica windows $1 \mathrm{~mm}$ apart, leaving $300 \mu \mathrm{L}$ of free volume for the sample. The wavelength used was $1.55 \AA$, and the nominal $q$-range was between 0.09 and $2.2 \mathrm{~nm}^{-1}$ (nominal $D_{\max } \leq 26 \mathrm{~nm}$ ). All experiments were performed at $25^{\circ} \mathrm{C}$.

Corrections of beam intensity, detector homogeneity, and sample absorption were performed, following standard procedures. Experiments were performed in a protein concentration range of $2.40-0.50 \mathrm{mg} / \mathrm{mL}$ to rule out a concentration effect. At least five independent curves were averaged for each single experiment. The size of proteins was determined from the gyration radii (RG) obtained by analysis of SAXS patterns as Guinier plots $\left(\ln (I)=\ln \left(I_{0}\right)-(1 / 3) * \mathrm{RG}^{2} * q^{2}, q=4 \pi \sin (\Theta) / \lambda, \mathrm{RG} *\right.$ $q \leq 1)$, and the globularity was evaluated by inspecting the Kratky plots $\left(I(q) * q^{2}\right.$ vs. $\left.q\right)$. A pair-distance distribution function (PDDF), obtained from scattering data, was calculated via regularized Fourier transform in the program GNOM 4.6 (Svergun 1992). A low-resolution three-dimensional model of the perivitellins was obtained with simulated annealing algorithms implemented in the program DAMMIF (Svergun 1999). SAXS data analysis was performed with ATSAS software, version 2.7.1 (Petoukhov et al. 2012). Data were deposited in the Small Angle Scattering Biological Data Bank (SASBDB).

Limited Proteolysis Using Proteinase K. To evaluate the susceptibility of native AG and egg perivitellins to aggressive protease digestion, a limited proteolysis with proteinase $\mathrm{K}$ was performed. Solutions containing $1 \mathrm{mg} / \mathrm{mL}$ of each perivitellin in $20 \mathrm{mM}$ Tris/ $\mathrm{HCl}$ buffer ( $\mathrm{pH} 8.5$ ), $25 \mathrm{mM} \mathrm{CaCl}_{2}$, and $10 \mathrm{mg} / \mathrm{mL}$ proteinase $\mathrm{K}$ (Promega) were incubated at $37^{\circ} \mathrm{C}$. Aliquots were taken at 10,20, and $40 \mathrm{~min}$, and enzyme activity was stopped by adding SDS sample buffer and boiling the mixture for $5 \mathrm{~min}$ at $100^{\circ} \mathrm{C}$. Samples were analyzed by SDS-PAGE with a $4 \%-20 \%$ polyacrylamide gradient.

\section{Functional Studies}

Either the AG soluble fraction or purified agPcOvo and agPcPV2 were subjected to the following functional experiments and compared with egg perivitellins.

Trypsin Inhibition Assay. Aliquots of the AG soluble fraction containing $79 \mu \mathrm{g}$ of protein were incubated with $4 \mu \mathrm{g}$ of trypsin for $5 \mathrm{~min}$, and trypsin inhibition was determined as previously described (Dreon et al. 2010), with slight modifications. In short, $\mathrm{N}$-benzoil-L-arginine ethyl ester (BAEE) was hydrolyzed by trypsin at the ester linkage, causing an absorbance increase at $253 \mathrm{~nm}$ at $25^{\circ} \mathrm{C}$. Results are expressed as units of activity (the amount of enzyme that causes an absorbance increase of $0.003 / \mathrm{min}$ ).

Simulated Gastrointestinal Digestion. In vitro simulated gastrointestinal digestion of the purified agPcOvo and agPcPV2, followed the method described by Moreno et al. (2005), with slight modifications. Briefly, gastric digestion was performed at $37^{\circ} \mathrm{C}$ for $120 \mathrm{~min}$ at $\mathrm{pH} 2.5$ in the presence of porcine pepsin (Sigma, catalog no. P 6887) at an enzyme:substrate ratio of 
$1: 20(\mathrm{w} / \mathrm{w})$. Aliquots were taken at 0,60 , and $120 \mathrm{~min}$ and analyzed by SDS-PAGE. For in vitro duodenal digestion, the 120 -min gastric digest was used as starting material. Pepsin activity was stopped by raising the $\mathrm{pH}$ to 8.5 with $0.1 \mathrm{M} \mathrm{NaOH}$ and $150 \mathrm{mM}$ Tris/ $\mathrm{HCl}$ buffer. The duodenal digestion was simulated by adding $0.25 \mathrm{M}$ taurocholic acid and trypsin from bovinez pancreas (Sigma, catalog no. T 9935) at an enzyme: substrate ratio of $1: 2.7(\mathrm{w} / \mathrm{w})$, at $37^{\circ} \mathrm{C}$. Aliquots were taken at 0,60 , and $120 \mathrm{~min}$ for SDS-PAGE analysis. Albumin was used as a positive (with enzyme) or negative (without enzyme) control in both gastric and duodenal digestion.

Toxicity Assay. All studies performed with murine animals were approved by the Comité Institucional para el Cuidado y Uso de Animales de Laboratorio (CICUAL; i.e., Institutional Animal Care and Use Committee) of the School of Medicine, Universidad Nacional de La Plata (UNLP; protocol P 01012016) and were carried out in accordance with the Guide for the Care and Use of Laboratory Animals (NIH 2011).

Female BALBc mice, 4 wk old and weighing 19-21 g, from a colony started with a stock provided by the US National Institutes of Health and bred in a specific pathogen-free environment were used. Groups of 10 animals were subjected to intraperitoneal injection with a single dose of $300 \mu \mathrm{L}$ phosphatebuffered saline or the same volume of five serial dilutions of the AG soluble fraction $(20,40,80,160$, and $320 \mu \mathrm{g}$ of total protein). The median lethal concentration $\left(\mathrm{LD}_{50}\right)$ was determined by a lethality test $96 \mathrm{~h}$ after administration, and the symptommonitoring behavior was chosen according to experimental data previously published (Heras 2008).

Data were analyzed by $t$-test with the software Instat 2.0 , with a $95 \%$ confidence interval. The bioassay statistics was performed with probit analysis implemented in the program TOXDAT (US Environmental Protection Agency), with 95\% of confidence limits.

\section{Results}

\section{Structural Characterization of AG Perivitellin Precursors}

Native Conformation, Size, and Global Shape. The electrophoretical mobility of ePcOvo and agPcOvo, as well as that of ePcPV2 and agPcPV2, showed no differences in native conditions. Furthermore, SDS-PAGE shows the same subunit composition for these perivitellins regardless of their origin (fig. 1). In addition, no differences could be detected between ePcOvo and agPcOvo or between ePcPV2 and agPcPV2 either in their charge surface or in their hydrodynamic volume, in anion exchange and size exclusion liquid chromatography, respectively (not shown).

The size and global shape of PcOvo and PcPV2 from eggs and AG were determined by SAXS. Experimental data normalized for protein concentration are presented as $\log _{10}(I(q))$-versus- $q$ plots for PcOvo (fig. 2A) and PcPV2 (fig. 2B) forms. Clearly, the curves for both perivitellins virtually overlap, indicating a comparable shape and size regardless of the origin. Moreover, from the Guinier-linearized region it was possible to fit the RG for the

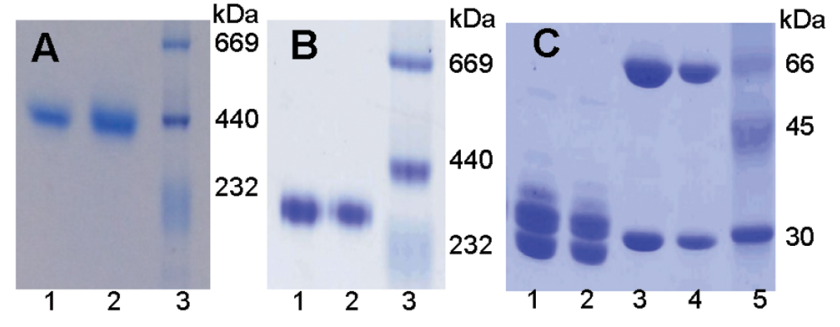

Figure 1. Electrophoretical comparison of albumen gland (ag) and egg (e) perivitellins ovorubin (PcOvo) and perivitellin-2 (PcPV2). $A$, Native $4 \%-20 \%$ polyacrylamide gel electrophoresis (PAGE). Lane 1: agPcPV2; lane 2: ePcPV2; and lane 3: molecular weight markers. $B$, Native 4\%-20\% PAGE. Lane 1: agPcOvo; lane 2: ePcOvo; and lane 3: molecular weight markers. $C$, Dissociating $4 \%-20 \%$ sodium dodecyl sulfate (SDS)-PAGE. Lane 1: agPcOvo; lane 2: ePcOvo; lane 3: agPcPV2; lane 4: ePcPV2; and lane 5: molecular weight markers.

proteins in a $q$ range between 0.1 and $0.38 \mathrm{~nm}^{-1}$ (insets in fig. $2 A$, $2 B)$. Slight significant differences were detected between ePcOvo $(42.30 \pm 0.07 \AA)$ and agPcOvo $(43.03 \pm 0.25 \AA)$, but not between ePcPV2 $(44.43 \pm 0.36 \AA)$ and $\operatorname{agPcPv} 2(44.54 \pm 0.28 \AA)$. The Kratky plots for the proteins (fig. A1; figs. A1, A2 available online) are bell shaped, as expected for globular proteins. Both perivitellins appear as anisometric particles with well-defined minor and major axes, as shown by their PDDFs (fig. 2C, $2 D$ ), where no significant differences were observed regarding their different origins (table 1). Both AG perivitellin models were quite similar to those of the egg forms (Dreon et al. 2008). SAXS data and models were deposited in the SASBDB, with accession codes SASDBW4 for agPcOvo and SASDBX4 for agPcPV2.

Secondary and Tertiary Structure. Absorption spectra of ePcOvo and agPcOvo in the UV-visible region were almost coincident, presenting four absorption maxima at $433,477,508$, and $541 \mathrm{~nm}$, indicating no differences in their carotenoid-binding site. Nevertheless, a higher intensity in agPcOvo spectra may be indicative of a higher carotenoid content (fig. $3 A$ ). Figure $3 B$ shows the fluorescence emission spectra of precursor and mature forms of PcOvo and PcPV2. Each perivitellin has a distinctive emission maximum, 325 and $332 \mathrm{~nm}$ for PcOvo and PcPV2, respectively, and presents nearly the same spectrum regardless of its origin, indicating no major differences in tertiary structure. Finally, farUV CD spectra showed no significant differences in the secondary structure between agPcOvo and ePcOvo or between agPcPV2 and ePcPV2 (fig. 3C).

Stability against $\mathrm{pH}$ and Aggressive Protease Treatment. The Trp fluorescence emission maxima observed for agPcOvo and agPcPV2 did not vary along the studied $\mathrm{pH}$ range (2.0-12.0), indicating that the Trp electronic environment is not affected (fig. 4). Interestingly, there was a variation in the fluorescence emission intensity between the recorded spectra for the two perivitellins. In a similar fashion, the absorbance intensity of carotenoid spectra decreased according to the $\mathrm{pH}$ value reduc- 



Figure 2. Size and global shape of ovorubin (PcOvo) and perivitellin-2 (PcPV2) determined by small-angle X-ray scattering (SAXS). $A, B, \mathrm{Raw}$ SAXS data, represented as $\log (I(q))$ versus $q$ for PcOvo and PcPV2, respectively. $C, D$, Pair-distance distribution obtained for PcOvo and PcPV2, respectively, using the program GNOM v4.5. Red lines: albumen gland precursors; black lines: egg mature perivitellins.

tion (data not shown), so the Trp fluorescence quenching by carotenoids is affected by $\mathrm{pH}$, which could explain PcOvo variation in fluorescence emission intensity.

In order to evaluate the relative exposure of these protein subunits to the solvent, as well as their flexibility, a proteinase $\mathrm{K}$ assay was performed (fig. 5). No differences in susceptibility could be observed between ePcOvo and agPcOvo or between ePcPV2 and agPcPV2. Both PcOvo forms were resistant to proteinase $\mathrm{K}$ digestion even when incubated for $40 \mathrm{~min}$ with $100 \mathrm{mg} / \mathrm{mL}$ of the enzyme, whereas BSA was completely digested in all conditions assayed (not shown). PcPV2 was not as resistant to proteinase $\mathrm{K}$ digestion as PcOvo, particularly its $67-\mathrm{kDa}$ subunit. However, there were no susceptibility differences between the two PcPV2 forms.

\section{Functional Characterization of AG Perivitellins}

Trypsin Inhibition. When trypsin was incubated in the presence of an AG soluble fraction, a high inhibitory activity was observed ( $69.79 \pm 1.25 \mathrm{U}$ reduced $/ \mathrm{mg}$ protein; $n=3)$, reaching up to $90 \%$ trypsin inhibition.
Simulated Gastrointestinal Digestion. We tested whether the antinutritional properties of ePcOvo and ePcPV2 are also present in their AG precursors with the use of a physiologically relevant digestion system. We found that both perivitellins resist simulated gastrointestinal digestion; however, PcPV2 forms are not impervious to pepsin (fig. 6).

Table 1: Comparison of the geometric parameters for the albumen gland and egg ovorubin and perivitellin-2 forms obtained from the PDDF of SAXS data

\begin{tabular}{lcc}
\hline Perivitellin form & $\begin{array}{c}\text { Minor axis } \\
(\AA)\end{array}$ & $\begin{array}{c}\text { Major axis } \\
(\AA)\end{array}$ \\
\hline Egg ovorubin & $52.5 \pm 1.0$ & $125.5 \pm 1.6$ \\
Albumen gland ovorubin & $52.3 \pm 1.2$ & $127.0 \pm 3.7$ \\
$\begin{array}{l}\text { Egg perivitellin-2 } \\
\begin{array}{l}\text { Albumen gland } \\
\text { perivitellin-2 }\end{array}\end{array}$ & $42.0 \pm .5$ & $166.1 \pm .7$ \\
\hline
\end{tabular}

Note. Values are the mean of five determinations $\pm 1 \mathrm{SD}$. PDDF $=$ pairdistance distribution function; SAXS = small-angle X-ray scattering. 

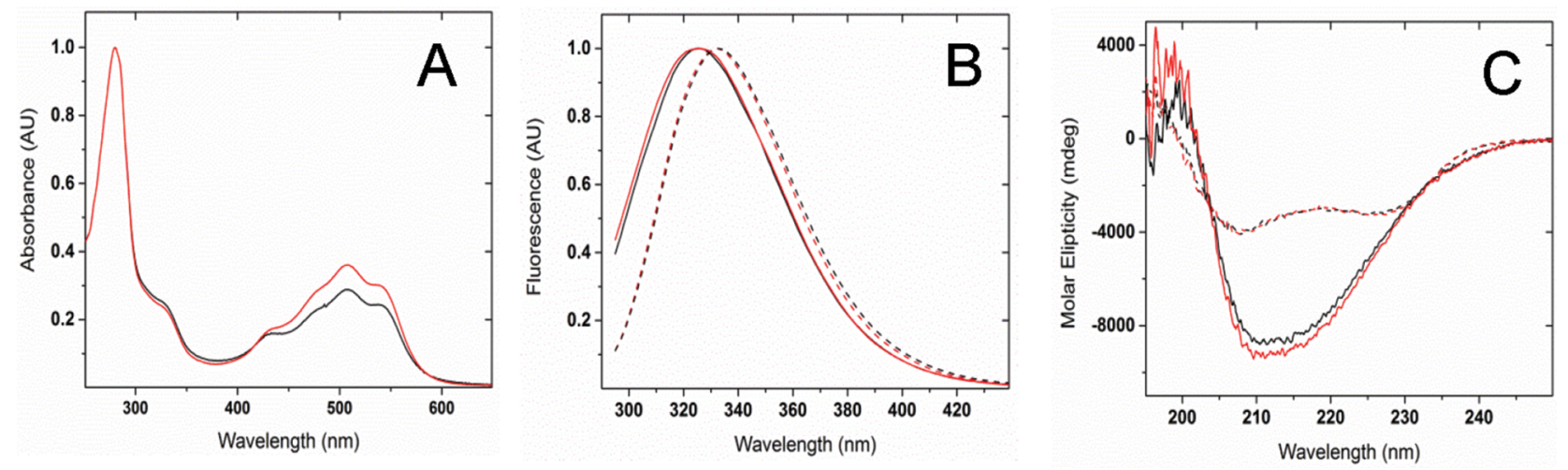

Figure 3. Spectroscopic comparison of albumen gland (ag) precursors and egg (e) perivitellins ovorubin (PcOvo) and perivitellin-2 (PcPV2). Absorption spectra $(A)$, fluorescence spectra $(B)$, and far-ultraviolet circular dichroism (UV-CD; $C$ ) spectra of agPcOvo (solid red line), ePcOvo (solid black line), agPcPV2 (dashed red line), and ePcPV2 (dashed black line). AU = arbitrary units.

Toxicity. The toxicity of the AG soluble fraction was evaluated by a lethality test. After $96 \mathrm{~h}$, an $\mathrm{LD}_{50}$ of $5.9 \mathrm{mg} / \mathrm{kg}$ was determined (fig. A2). Treated mice showed changes in their clinical and behavioral signs that included hypothermia, weakness, lethargy, bent-down (orthopenic) position, closed eyes, tachipnea, spastic movements (tremors), and shaggy hair similar to those observed for egg perivitelline fluid.

\section{Discussion}

The substantial structural changes of vitellin extraovarian precursors (vitellogenins) have been extensively studied in invertebrates (Raikhel and Sappington 2002), but these posttranslational modifications were unclear for gastropods having an AG. We addressed this question by structure-function analysis of the AG precursors of the two most abundant and best-studied egg proteins in Pomacea canaliculata, PcOvo and PcPV2, with the result that they were almost identical to their egg mature forms. Thus, the AG stores fully mature perivitellins with no proteolytic processing or any other major structural change to an inactive precursor that could have been easily detected with the biophysical and biochemical techniques employed. Both PcOvo forms present the same size, global shape, apoprotein composition, subunit mass, and proteinase $\mathrm{K}$ susceptibility, strongly suggesting that the slight RG difference is due not to a polypeptide chain cleavage or other large structural changes but probably to a differential glycosylation of PcOvo forms. Another minor difference found between $\mathrm{PcOvo}$ forms was the higher carotenoid content of agPcOvo, probably caused by a pigment degradation within the egg rather than by a structural difference from the precursor. In this regard, it is worth recalling that eggs are exposed to a hostile environment including solar radiation and high temperatures, which are known to degrade ePcOvo labile carotenoids (Dreon et al. 2004). Likewise, no major differences between PcPV2 forms were detected at any of the evaluated structural levels, suggesting that agPcPV2 also has the structural conformation of the egg mature perivitellin (Frassa et al. 2010). As form fits function, this lack of structural differences was reflected in the biological activity of both proteins within the AG. Thus, the neurotoxic activity of the AG soluble protein fraction on mice was confirmed. Considering its agPcPV2 content $\left(2.6 \% \mathrm{w} / \mathrm{w}\right.$ of the total AG protein; Dreon et al. 2002), an $\mathrm{LD}_{50}$ similar to that reported for ePcPV2 (Heras et al. 2008) was obtained, which is comparable to the toxicity level of snake venom compounds (Butzke and Luch 2010). In addition, treated mice displayed neurological signs similar to those exerted by ePcPV2 (Heras et al. 2008). Both perivitellin precursors were resistant to simulated gastrointestinal digestion and stable in a wide $\mathrm{pH}$ range, suggesting they could reach the intestine of a potential snail predator in their fully noxious forms, as their egg forms do (Dreon et al. 2008, 2013). Furthermore, the AG soluble fraction is capable of limiting predators' ability to digest nutrients, as suggested by its strong trypsin inhibition activity.

Decades of fieldwork observations indicate that predators of adult apple snails discard the AG when feeding on females (Snyder and Kale 1983; Sykes 1987; Yusa et al. 2000). Except for species of the genus Pomacea, there are no reports of such behavior with respect to other gastropods, even within other animals in the family Ampullariidae. For instance, Marisa cornuarietis and Pomacea are both preyed on by snail kites, but no AG rejection was ever observed when kites fed on Marisa (Snyder and Kale 1983). Probably the perivitellins of Marisa non-aposematic eggs are nontoxic. It was demonstrated in P. canaliculata that there is no perivitellin synthesis outside the AG and no hemolymph circulation of perivitellin or perivitellin precursors, something that probably extends to other gastropods (Dreon et al. 2002, 2003). Therefore, as the noxious perivitellin precursors are exclusively confined within the AG, this explains why it is the only usually discarded organ, even when this behavior implies a large loss of the total energy and nutrients available from the soft-body biomass (Estoy et al. 2002). Finally, we propose that the reddishpink gland color may contribute to this behavior, helping the visual-hunting predators of adult snails to associate the bright AG color with the noxious compounds it carries.

Gastropods are the most successful class of mollusks and the only ones with terrestrial forms (de Jong-Brink et al. 1983). 




This content downloaded from 132.239.001.231 on April 18, 2017 06:21:11 AM 
It has been well established that internal fertilization, direct development, and a female accessory AG that secretes an egg coat of perivitelline fluid allowed gastropod success in a wide range of environments (Runham 1988). To the best of our knowledge there is, however, no other report demonstrating by comparative structure-function analysis that perivitellin precursors in AG do not experience large structural processing. A literature survey showed that functional perivitellin precursors were reported in the AGs of a few other snails from marine, freshwater, and terrestrial environments that belong to the Pulmonata and Opisthobranchia clades (Takamatsu et al. 1995; Nagle et al. 2001; Mukai et al. 2004; Sanchez et al. 2006; Hathaway et al. 2010). Though from a different context, these findings suggest that the vitellogenic mechanism found in apple snails, which belong to the clade Caenogastropoda, may be more widespread among gastropods, contributing to the reproductive success of the group, currently the second most species-rich group of animals after insects.

\section{Conclusion}

To comprehend the evolutionary forces that shaped metazoan life-history patterns, one must consider the role played by reproductive strategies, especially the diverse mechanisms of egg yolk synthesis that have arisen through selection. This study provides the first piece of evidence that the AG produces perivitellin precursors functionally and structurally similar to mature perivitellins. This suggests that those gastropods with an AG have developed an alternative vitellogenic mechanism without the large perivitellin precursor processing typical of invertebrate egg yolk vitellin maturation. This is probably a more efficient and faster mechanism for food conversion into egg production. By this mechanism Pomacea canaliculata stores the noxious proteins of the eggs inside the AG, a likely explanation for the feeding



Figure 5. Limited proteolysis analysis by proteinase $\mathrm{K}$ digestion. The protein solution $(1 \mathrm{mg} / \mathrm{mL})$ was incubated with proteinase $\mathrm{K}$ at different times. Products were analyzed on an sodium dodecyl sulfate polyacrylamide gel (4\%-20\%) and visualized with Coomassie Brilliant Blue R-250. $A$, ovorubin forms ( $\mathrm{ag}=$ albumen gland precursor; $\mathrm{e}=$ egg mature); $B$, perivitellin-2 forms.

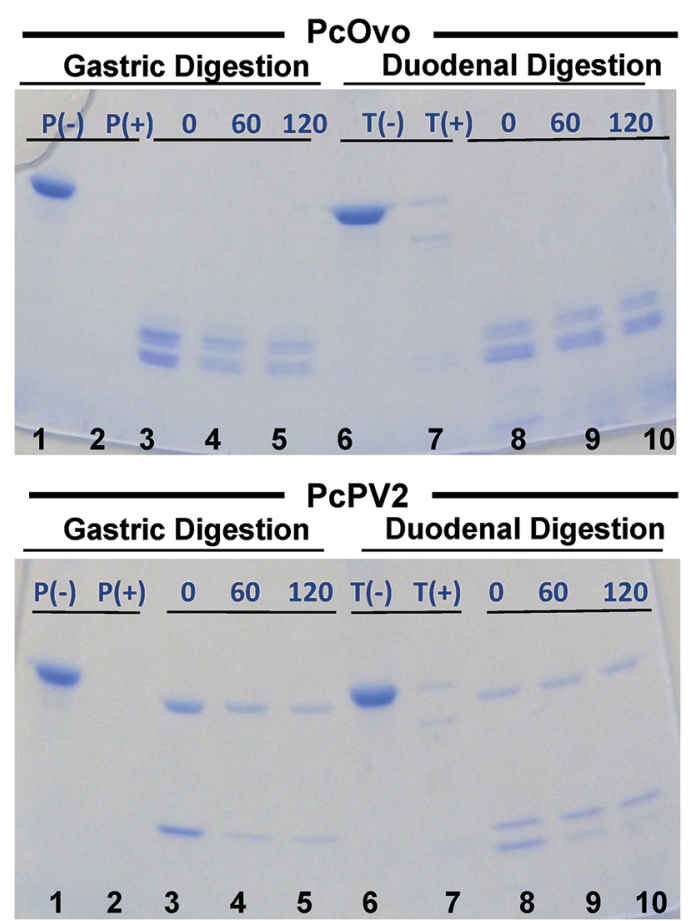

Figure 6. Simulated gastrointestinal digestion of albumen gland (ag) perivitellins ovorubin (PcOvo) and perivitellin-2 (PcPV2). Lanes 1, 2: Bovine serum albumin (BSA)-negative and BSA-positive controls of gastric digestion; lanes 3-5: agPcPV2 subunits (31 and $67 \mathrm{KDa}$ ) and agPcOvo subunits (28-35-KDa range) after incubation with pepsin for 0, 60, and $120 \mathrm{~min}$. Lanes 6, 7: BSA-negative and BSA-positive controls of duodenal digestion; lanes 8-10: agPcPV2 and agPcOvo digested with trypsin for 0,60 , and $120 \mathrm{~min}$. Note the faint trypsin band under the $31-\mathrm{KDa}$ agPcPV2 in lanes 8-10.

behavior of predators that avoid eating the gland while consuming the rest of the snail female body.

Further perivitellin structure-function studies in other gastropods with the same and different oviposition strategies are necessary to confirm this finding. Among apple snails, more work regarding comparative reproductive biology at the molecular level would be valuable, considering that reproduction has a high significance for understanding distribution patterns, invasion biology, and possibly the evolution of the amphibious trait seen in most members of Ampullariidae.

\section{Acknowledgments}

H.H. and M.S.D. are members of the Carrera del Investigador CONICET, Argentina, and the Centro de Investigaciones, Instituto Clínico de Buenos Aires (CICBA), Argentina, respectively. M.P.C. is a doctoral fellow at CONICET, Argentina. We thank the Laboratório Nacional de Luz Síncrotron, the Brazilian Synchrotron Light Laboratory (project SAXS1-15958). We thank Dr. J. M. Lofeudo for his help in the toxicity bioassay, Dr. G. Franchini for her suggestions, and Dr. M. Ermacora for his fruitful comments. This work was supported by a grant from the Agencia Nacional de Promoción Científica y Técnica, Argentina (project PICT 1428). The funders had no role in study design, 
data collection and analysis, decision to publish, or preparation of the manuscript.

\section{Literature Cited}

Butzke D. and A. Luch. 2010. High-molecular weight protein toxins of marine invertebrates and their elaborate modes of action. Pp. 213-232 in A. Luch, ed. Clinical toxicology. Vol. 2 of Molecular, clinical and environmental toxicology. Birkhäuser, Basel, Switzerland.

Catalán M., M.S. Dreon, H. Heras, R.J. Pollero, S.N. Fernández, and B. Winik. 2006. Pallial oviduct of Pomacea canaliculata (Gastropoda): ultrastructural studies of the parenchymal cellular types involved in the metabolism of perivitellins. Cell Tissue Res 324:523-533.

Cowie R.H. 2002. Apple snails (Ampullariidae) as agricultural pests: their biology, impacts, and management. Pp. 145-192 in G.M. Baker, ed. Molluscs as crop pests. CABI, Wallingford, UK.

Davis B. 1964. Disc electrophoresis. II. Method and application to human serum proteins. Ann NY Acad Sci 121:404-428.

de Jong-Brink M., H.H. Boer, and J. Joosse. 1983. Mollusca. Pp. 297-355 in K.G. Adiyodi and R.G. Adiyodi, eds. Oogenesis, oviposition and oosorption. Vol. I of Reproductive biology of invertebrates. Wiley, New York.

Dreon M., S. Lavarias, C.F. Garin, H. Heras, and R.J. Pollero. 2002. Synthesis, distribution, and levels of an egg lipoprotein from the apple snail Pomacea canaliculata (Mollusca: Gastropoda). J Exp Zool 292:323-330.

Dreon M.S., P.E. Fernández, E.J. Gimeno, and H. Heras. 2014. Insights into embryo defenses of the invasive apple snail Pomacea canaliculata: egg mass ingestion affects rat intestine morphology and growth. PLoS Negl Trop Dis 8(6): e2961. doi:10.1371/journal.pntd.0002961.

Dreon M.S., M.V. Frassa, M. Ceolin, S. Ituarte, J.W. Qiu, J. Sun, P.E. Fernández, and H. Heras. 2013. Novel animal defenses against predation: a snail egg neurotoxin combining lectin and pore-forming chains that resembles plant defense and bacteria attack toxins. PLoS ONE 8(5):e63782. doi: 10.1371/journal.pone.0063782.

Dreon M.S., H. Heras, and R.J. Pollero. 2003. Metabolism of ovorubin, the major egg lipoprotein from the apple snail. Mol Cell Biochem 243:9-14.

Dreon M.S., S. Ituarte, M. Ceolín, and H. Heras. 2008. Global shape and $\mathrm{pH}$ stability of ovorubin, an oligomeric protein from the eggs of Pomacea canaliculata. FEBS J 275:4522-4530.

Dreon M.S., S. Ituarte, and H. Heras. 2010. The role of the proteinase inhibitor ovorubin in apple snail eggs resembles plant embryo defense against predation. PLoS ONE 5(12): e15059. doi:10.1371/journal.pone.0015059.

Dreon M.S., G. Schinella, H. Heras, and R.J. Pollero. 2004. Antioxidant defense system in the apple snail eggs, the role of ovorubin. Arch Biochem Biophys 422:1-8.

Eckelbarger K.J. 1994. Diversity of metazoan ovaries and vitellogenic mechanisms: implications for life history theory. Proc Biol Soc Wash 107:193-218.
Estoy J., Y. Yusa, T. Wada, H. Sakurai, and K. Tsuchida. 2002. Effects of food availability and age on the reproductive effort of the apple snail, Pomacea canaliculata (Lamarck) (Gastropoda: Ampullariidae). Appl Entomol Zool 37:543-550.

Frassa M.V., M. Ceolín, M.S. Dreon, and H. Heras. 2010. Structure and stability of the neurotoxin PV2 from the eggs of the apple snail Pomacea canaliculata. Biochim Biophys Acta 1804:1492-1499.

Garín C.F., H. Heras, and R.J. Pollero. 1996. Lipoproteins of the egg perivitellin fluid of Pomacea canaliculata snails (Mollusca: Gastropoda). J Exp Zool 276:307-314.

Hathaway J.J., C.M. Adema, B.A. Stout, C.D. Mobarak, and E.S. Loker. 2010. Identification of protein components of egg masses indicates parental investment in immunoprotection of offspring by Biomphalaria glabrata (Gastropoda, Mollusca). Dev Comp Immunol 34:425-435.

Hayes K.A., R.L. Burks, A. Castro-Vazquez, P.C. Darby, H. Heras, P.R. Martín, J.W. Qiu, et al. 2015. Insights from an integrated view of the biology of apple snails (Caenogastropoda: Ampullariidae). Malacologia 58:245-302.

Heras H., M.S. Dreon, S. Ituarte, and R.J. Pollero. 2007. Egg carotenoproteins in Neotropical Ampullariidae (Gastropoda: Architaenioglossa). Comp Biochem Physiol C 146:158-167.

Heras H., M.V. Frassa, P.E. Fernández, C.M. Galosi, E.J. Gimeno, and M.S. Dreon. 2008. First egg protein with a neurotoxic effect on mice. Toxicon 52:481-488.

Heras H., C.F. Garín, and R.J. Pollero. 1998. Biochemical composition and energy sources during embryo development and in early juveniles of the snail Pomacea canaliculata (Mollusca: Gastropoda). J Exp Zool 280:375-383.

Laemmli U.K. 1970. Cleavage of structural proteins during the assembly of the head of bacteriophage T4. Nature 227:680685.

Lowry O.H., N.J. Rosenbrough, A.L. Farr, and R. Randall. 1951. Protein measurement with the Folin phenol reagent. J Biol Chem 193:265-275.

Lv S., Y. Zhang, H.X. Liu, C.W. Zhang, P. Steinmann, X.N. Zhou, and J. Utzinger. 2009. Angiostrongylus cantonensis: morphological and behavioral investigation within the freshwater snail Pomacea canaliculata. Parasitol Res 104:13511359.

Margolis J. and C.W. Wrigley. 1975. Improvement of pore gradient electrophoresis by increasing the degree of crosslinking at high acrylamide concentration. J Chromatogr 105: 204-209.

Moreno F.J., F.A. Mellon, M.S. Wickham, A.R. Bottrill, and E.N. Mills. 2005. Stability of the major allergen Brazil nut $2 S$ albumin (Ber e 1) to physiologically relevant in vitro gastrointestinal digestion. FEBS J 272:341-352.

Mukai S.T., T. Hoque, F. Morishita, and A.S. Saleuddin. 2004. Cloning and characterization of a candidate nutritive glycoprotein from the albumen gland of the freshwater snail, Helisoma duryi (Mollusca: Pulmonata). Invertebr Biol 123: 83-92.

Nagle G.T., M. de Jong-Brink, S.D. Painter, and K.W. Li. 2001. Structure, localization and potential role of a novel mol- 
luscan trypsin inhibitor in Lymnaea. Eur J Biochem 268: 1213-1221.

NIH (National Institutes of Health). 2011. Guide for care and use of laboratory animals. Academic Press, Washington.

Petoukhov M.V., D. Franke, A.V. Shkumatov, G. Tria, A.G. Kikhney, M. Gajda, C. Gorba, et al. 2012. New developments in the ATSAS program package for small-angle scattering data analysis. J Appl Crystallogr 45:342-350.

Raikhel A.S. and T.W. Sappington, eds. 2002. Progress in vitellogenesis. Vol. XII, Pt. A of Reproductive biology of invertebrates. Science, Enfield, NH.

Runham N. 1988. Mollusca. Pp. 1-28 in K.G. Adiyodi and R.G. Adiyodi, eds. Accessory sex glands. Vol. III of Reproductive biology of invertebrates. Wiley, New York.

Sanchez J.F., J. Lescar, V. Chazalet, A. Audfray, J. Gagnon, R. Alvarez, C. Breton, A. Imberty, and E.P. Mitchell. 2006. Biochemical and structural analysis of Helix pomatia agglutinin: a hexameric lectin with a novel fold. J Biol Chem 281:20171-20180.

Snyder N.F.R. and H.W. Kale. 1983. Mollusk predation by snail kites in Colombia. Auk 100:93-97.

Sun J., M. Wang, H. Wang, H. Zhang, X. Zhang, V. Thiyagarajan, P.Y. Qian, and J.W. Qiu. 2012a. De novo assembly of the transcriptome of an invasive snail and its multiple ecological applications. Mol Ecol Resour 12:1133-1144.

Sun J., H. Zhang, H. Wang, H. Heras, M.S. Dreon, S. Ituarte, T. Ravasi, P.Y. Qian, and J.W. Qiu. 2012b. First proteome of the egg perivitelline fluid of a freshwater gastropod with aerial oviposition. J Proteome Res 11:4240-4248.

Svergun D.I. 1992. Determination of the regularization parameter in indirect-transform methods using perceptual criteria. J Appl Crystallogr 25:495-503.

. 1999. Restoring low resolution structure of biological macromolecules from solution scattering using simulated annealing. Biophys J 76:2879-2886.

Sykes P.W., Jr. 1987. The feeding habits of the snail kite in Florida, USA. Colon Waterbirds 10:84-92.

Takamatsu N., T. Shiba, K. Muramoto, and H. Kamiya. 1995. Molecular cloning of the defense factor in the albumen gland of the sea hare Aplysia kurodai. FEBS Lett 377:373-376.

Tanaka M.O., A.L.T. Souza, and E.S. Modena. 2006. Habitat structure effects on size selection of snail kites (Rostrhamus sociabilis) and limpkins (Aramus guarauna) when feeding on apple snails (Pomacea spp.). Acta Oecol 30:88-96.

Wallace R.A., S.L. Walker, and P.V. Hauschka. 1967. Crustacean lipovitellin: isolation and characterization of the major high-density lipoprotein from eggs of decapods. Biochemistry 6:1582-1590.

Yusa Y. 2001. Predation on eggs of the apple snail Pomacea canaliculata (Gastropoda: Ampullariidae) by the fire ant Solenopsis geminata. J Molluscan Stud 67:275-279.

Yusa Y., N. Sugiura, and K. Ichinose. 2000. Predation on the apple snail, Pomacea canaliculata (Ampullariidae), by the Norway rat, Rattus norvegicus, in the field. Veliger 43:349-353. 